\title{
MAPEAMENTO DOS SOLOS DA BACIA DO RIBEIRÃO PANGA
}

\author{
Samuel do Carmo Lima \\ Doutorando em Geografia Física/USP(SP) \\ Prof. Depto. Geogrfia -UFU
}

Andréa Ríspoli Bernardino

Bolsista I.C./CNPq

E-mail: Samuel @ BRUFU

RESUMO: Os solos da bacia do Ribeirão Panga sāo predominantemente Latossolos Vermelho-amerelo textura arenosa e textura média, distróficos, com baixo teor de matéria orgânica, baixo teor de bases trocáveis e medianamente ácidos. A natureza desses solos reflete uma pedogênese tropical com intenso processo de lixiviação. Solos hidromórficos podem ser encontrados nos vales de fundo chato com vereda, onde o lençol freático permanece aflorado durante $o$ ano todo.

Palavras chaves: Latossolos, lixiviação, distrofismo.

ABSTRACT: The soils of River Panga basin are mainly loamy sandy and sandy loam Red yellow Latosol distrophics with a low level of exchangeable bases and organic matter, being acids soils. The soil nature reflect a tropical pedogenesis with intensive lessivage. Hidromorphics soils can be found on flat valleys with "vereda" and drainage limitations.

Keywords: Latossols, lessivage, distrophism

\section{1 - INTRODUÇÃO}

ORibeirão Panga nasce nos setores sudoesse do município de Uberlândia, nos limites com o município de Uberaba, na fazenda Jatai, nas coordenadas geográficas de $19^{\circ} 15^{\prime}$ de latitude sul e $48^{\circ} 17^{\prime}$ de longitude oesse de Greenwich. Seu perfil longitudinal possui uma amplitude altimétrica de 210 metros numa extensāo de 51 quilômetro. Nasce numa altitude de 880 metros e sua foz está à uma altitude de 670 metros, no Ribeirão Douradinho.

É afluente do Ribeirão Douradinho, que por sua vez é afluente do Rio Tijuco, que é tributário do Rio Paranaiba. O Ribeirão Panga corre paralelamente ao Ribeirão Douradinho e ao Rio Tijuco. O paralelismo dessa bacia em relaçáo às suas vizinhas é nitidamente observado nas fotografias aéreas e nas imagens TM/Landsat, 0 que é explicado por um condicionamento estrutural promovido por amplos falhamentos geológicos.

O Ribeirão Panga corre em trajetos retilínios, na direção SE-NW, apresentando um desvio para sudoesse no médio curso, a jusante da Essação Ecológica do Panga, no nível topográfico de 750 metros, com uma inflexão de $90^{\circ}$. Retoma a direção inicial, a mais ou menos $6 \mathrm{~km}$ à jusante, sob a altitude de 700 metros. Isto é mais uma evidência de que a bacia está submetida a um controle estrutural de linhas de falhas. Em trechos do baixo curso seu trajeto é meandrante livre.

A área da bacia do Ribeirão Panga é de 234 $\mathrm{km}^{2}$, com altitudes variando entre 902 e 682 metros. O clima, segundo a classificação de Köppen, é do tipo Aw megatérmico, com veróes chuvosos e estiagem no inverno que dura de 4 a 5 meses. $A$ temperatura média anual é de $22^{\circ} \mathrm{C}$ e o total pluviométrico é de $1500 \mathrm{~mm} / \mathrm{ano}$ (ROSA, LIMA \& ASSUNÇĀO 1991).

Segundo Nishyiama (1989), a geologia na bacia do Ribeirão Panga é representada pela seguinte compartimentação geológica: Nas áreas

Sociedade \& Natureza, Uberlândia, 4 (7 e 8): 85-98, janeiro/dezembro 1992 
de topos encontram-se as coberturas detritolateríticas Terciárias e Quaternárias indiferenciadas, que a nosso ver não é nada mais que uma cobertura pedológica profunda sobre rochas das Formaçōes Marília e Adamantina; nas vertentes encontra-se a Formação Adamantina, que é recoberta pela Formação Marília em altitudes acima de 800 metros; no vale do Ribeirão Panga e nos seus maiores afluentes podemos encontrar, em trechos descontínuos, aluviōes holocênicos; No leito do Ribeirāo Panga afloram basaltos da Formação Serra Geral, configurandose dois derrames. $O$ primeiro trecho está situado entre 740 a 750 metros de altitude, a cerca de $2 \mathrm{~km}$ a jusante da Essação Ecológica do Panga. O segundo trecho está situado abaixo da cota topográfica de 700 metros, já no baixo curso, chegando quase àfoz do Ribeirāo Panga, que está sobre aluviōes.

As nascentes dos córregos que desaguam no Ribeirão Panga quase sempre se apresentam com cabeceiras arredondadas, em "dales" - pequenos anfiteatros comsolos hidromórficos. Algumas vezes sāo múltiplas para o mesmo canal. Outras vezes, porém, apresentam formas mais estreitas e afuniladas.

Ao longo desses córregos podem aparecer veredas, nas planícies aluviais com solos hidromórficos. As veredas são um subsistema úmido dentro do cerrado carcaterizadas por uma vegetação predominantemente herbácea, com gramíneas e buritizais. Esses cursos d'água que em geral são de pequena extensão, variando de 1500 a 2000 metros, nascem nas áreas de topos, com declividades inferiores a $3 \%$, ou no terço médio superior das vertente, com declividades variando entre 3 e $6 \%$, com rupturas de declive.

Nos setores do Ribeirão Panga onde o vale é mais encaixado, com solos bem drenados, pode aparecer uma mata ciliar, comepífitas e pterodófitas em abundância. Onde o vale é mais amplo e com fundo chato, com solos hidromórficos, a mata ciliar é substituida por vereda. Os afluentes do Ribeirão Panga quase sempre são drenagens de $1^{\circ}$ ordem, com vales amplos e de fundo chato, com solos hidromórficos e veredas.

Nas superfícies mais elevadas, constituídas de topos aplainados e suavemente ondulados, a dissecação é incipiente, pois as condiçōes de drenagem dos solos são boas. Os solos são Latossolos Vermelho-amarelos textura média e. textura arenosa, com teores médios de areia variado em torno de $75 \%$, podendo chegar a valores superiores a $80 \%$.

As vertentes são levemente convexas com declividades que em geral sāo inferiores a $6 \%$, mas podem se apresentar com rupturas de declive, abaixo das quais as declividades podem chegar a mais que $12 \%$. Tornam-se côncavas, mas logo a seguir retilíneas, com declividades mais suaves.

As rupturas de declive só aparecem a partir do médio curso e são marcadas pelo afloramento de uma couraça cascalhenta e concrecionada no terço superior das vertentes, por vezes formando pequenos anfiteatros de bordas abauladas. É preferencialmente nos materiais arenosos e cascalhentos que a precipitação ferruginosa pode resultar em crostas noduladas e escoriáceas. Nesses anfiteatros, sobre couraças, os solos sāo dominantemente hidromórficos, relacionados com a translocaçāo da água, em lençol suspenso. Logo abaixo das rupturas a vertente torna-se convexa, com uma pequena rampa coluvionada. As couraças ferruginosas, produto da pedogênese de regiōes tropicais, em clima essacional, são formadas por um processo que é guiado pela alternância de períodos úmidos e secos.

A declividade do relevo controla o escoamento superficial e a infiltração da água pluvial; porisso é um dos elementos da paisagem que estāo relacionados com a essabilidade das vertentes, principalmente no que se refere aos processos erosivos de sulcos, ravinas e voçorocas. As vertentes são partes integrantes das bacias hidrográficas e há, sem dúvida, relaçóes entre elas e a rede de drenagem. Por exemplo, há uma relação evidente entre o comprimento e a declividade das vertentes com a densidade de drenagem (CHRISTOFOLETTI 1974).

O relevo da bacia do Ribeirão Panga é plano e subplano em $46,4 \%$ de sua área, que possui declividades menores que $3 \%$, onde é baixo o grau de entalhamento fluvial. No alto curso predominam pequenas colinas de topos planos reduzidos, quase arredondados, vertentes suavemente convexas, e vales em "V". Essas áreas encontram-se em altitudes superiores a 800 metros. A partir do médio curso, os topos são planos e mais extensos. Em 
$43,0 \%$ da área da bacia do Ribeirāo Panga as declividades situam-se entre 3 e $9 \%$, representando vertentes convexas suaves. Quase $90 \%$ de sua área possui declividades iguais ou inferiores a $9 \%$. Somente nos setores de ruptura de declive, que aparecem margeando o Ribeirāo Panga, em seu médio curso, na confluência desse com alguns tributários, as declividades são superiores a $9 \%$ e raramente ultrapassam a $12 \%$.

\section{2 - MATERIAIS E MÉTODO}

Utilizamos imagens de TM/LANDSAT 5, escala 1:50.000, composiçāo colorida (falsa cor), bandas 3,4 e 5 , de $30 / 7 / 90$, e as folhas topográficas do DSG, escala 1:25.000, para traçar a drenagem, as principais estradas, delimitar as unidades fisiográficas da área de estudo, e mapear os solos hidromórficos. Utilizamos também as fotografias aéreas pancromáticas de 1979, na escala de 1:25.000, do Instituto Brasileiro do Café/GERCA com essereoscópio de espelho, para compartimentação topomórfica e para definir os pontos de observação de campo e coleta de amostras. As fotografia aéreas foram utilizadas, também, para delimitação das unidades pedológicas com base na identificação das unidades fisiográficas da paisagem na área de estudos. Através de umlevantamento exploratório, essabeleceu-se a legenda preliminar que foi aperfeiçoada com o levantamento sistemático.

No levantamento sistemático verificamos os pontos assinalados na fotointerpretação e delimitamos, no mapa, com mais precisão, as unidades da legenda. As observaçōes de campo para descrição morfológica dos solos foram realizadas em 24 perfis, em trincheiras e cortes de estrada, além de inúmeras tradagens. Foram coletadas amostras referentes aos horizontes e sub-horizontes de cada perfil observado, que foram acondicionadas em sacos plásticos, devidamente etiquetadas e, posteriormente, levadas ao laboratório para análises físicas e químicas. Nos trabalhos de campo foram utilizados trados do tipo holandês, enxadão, facas, lupas, carta de cor de MUNSEL, clinômetro, bússola, caderneta de campo, etc.

As amostras foram secas ao ar, destorroadas e passadas em peneira com abertura de $2 \mathrm{~mm}$ de diâmetro. Na fração inferior a $2 \mathrm{~mm}$ (terra fina seca ao ar) foram feitas as determinaçōes físicas e químicas conforme procedimentos descritos por EMBRAPA (1979a).

A seqüência de horizontes observada foi $A$ - $B$, e devido à profundidade do solo nāo foi observado o horizonte C. A identificaçāo dos solos se baseou nos conceitos de classes de solos essabelecidos pela equipe de pedologia do Serviço Nacional de Levantamento e Conservaçāo do Solos - SNLCS/ EMBRAPA (EMBRAPA 1979b).

\section{3 - RESULTADOS E DISCUSSÃO}

Segundo RADAMBRASIL (1983), em mapa de solos da Folha Goiânia, na escala ao milhonésimo, os solos da bacia do Ribeirāo Panga são Latossolos Vermelho-amarelos distróficos e álicos de textura média, com inclusóes de Areias Quartzosas distróficas e solos hidromórficos gleizados distróficos; Latossolos Vermelho-escuros distróficos e álicos textura argilosa; e Latossolos Roxo distróficos e TerraRoxa Estruturada eutrófica, ambos textura muito argilosa e argilosa.

EMBRAPA (1982), em mapa de solos na escala 1:500.000, identifica os solos da bacia do Panga como sendo Latossolos Vermelho-escuros distróficos e álicos textura média.

De certa forma, o levantamento de solos realizado nesse trabalho contraria os levantamentos anteriores. Há que se levar em conta que os trabalhos anteriores foram realizados para áreas muito amplas, em uma escala muito pequena. A escala de trabalho desse levantamento foi 1:50.000 e a escala de apresentação do mapa $1: 100.000$.

Os solos encontrados na bacia do Ribeirão Panga foram identificados como Latossolo Vermelho-Amarelo distrófico textura média; Areias Quartzosas distróficas com inclusóes de Latossolo Vermelho-amarelo distrófico textura arenosa; e Solos Hidromórficos textura arenosa (cf. Mapa de Solos da Bacia do Ribeirão Panga).

Os Latossolos sāo solos com B latossólico, que correspondem ao "oxic horizon" da Soil Taxonomic (SOILSURFE STAFF 1975). Estão incluídos nessa classe os seguintes solos: Latossolo amarelo, Latossolo Vermelho amarelo, Latossolo Vermelho Escuro, Latossolo roxo, que se diferenciam pela cor, que é relativamente 
correlacionável ao teor de ferro. Os Latossolos são solos minerais, profundos, com B latossólico, porosos, bem drenados e com uma seqüência de horizontes $A, B$ e $C$ muito homogênea, em se tratando de cor e textura, com estrutura microagregada.

Esses solos apresentam baixo conteúdo de minerais primários, com exceção dos muito resistentes ao intemperismo. A fração argila é constituída, basicamente, por minerais do tipo caulinita e por sesquióxidos. Sāo geralmente ácidos, com baixa saturação de bases, o que indica baixa fertilidade natural. Os Latossolos se distribuem em uma área equivalente a $46 \%$ da área total ocupada pelos cerrados (GOEDERT 1986).

Os solos hidromórficos correspondem àqueles que sofrem grande influência do lençol freático, refletida no perfil pela forte gleização, presença de horizonte glei e/ou grande acúmulo de matéria orgânica nos primeiros $60 \mathrm{~cm}$ de profundidade.

\section{1 - Areias Quartzosas}

Essa unidade apresenta Areias Quartzosas distróficas com inclusōes de Latossolos Vermelhoamarelos de textura arenosa, de cor 7,5YR e 5YR bem homogênea ao longo do perfil. Os teores de argila crescem da superfície para a base, porém de maneira pouco significativa. A distribuição dos teores de argila entre os horizontes $A$ e $B$, com baixa gradiência, evidencia a fraca mobilidade das argilas ao longo do perfil. A relação silte/argila é baixa. Esses solos ocupam umaárea de $14,31 \mathrm{Km}^{2}$, equivalente a $6,1 \%$ da área total da bacia.

O horizonte $A$ possui espessura variando de 15 a $30 \mathrm{~cm}$, com transiçáo clara e plana para o horizonte B. O horizonte B possui espessura média variando entre 30 e mais que $180 \mathrm{~cm}$ de profundidade. A estrutura no horizonte $A$ é fraca pequena granular, friável. A consistência é macia, não plástica e não pegajosa. As cores são bruno avermelhado 5YR 4/4, bruno escuro 7,5 YR 3/4 a 4/4, e bruno amarelado escuro 10 YR $3 / 4$ a $4 / 4$ em alguns perfis, levemente mais escurecido que 0 horizonte $B$, demonstrando um baixo conteúdo de matéria orgânica. A estrutura do horizonte $B$ é muito pequena, granular, com aspecto maciça porosa pouco coerente. A consistência é semelhante à do horizonte $A$, ou seja, é macia, não plástica e nāo pegajosa. As cores são bruno escuro a bruno forte 7,5 YR 4/4 a 4/8 em alguns perfis e vermelho amarelo $5 Y R$ R/6 a $5 / 8$, noutros.

A textura do horizonte $A$ apresenta teores de areia variando de 78,6 a $94,0 \%$, com um teor médio de $80 \%$ e teores de argila que variam de 6,1 a $15,8 \%$ com um teor médio de $12,2 \%$. A textura do horizonte $B$ apresenta teores de areia variando de 75,8 a $89,7 \%$, com um teor médio de $79,4 \%$. Os teores de argila variam de 8,4 a $21 \%$, com um teor médio de 13,7\% (cf. tabela 1 e 2).

Os valores de $\mathrm{pH}\left(\mathrm{em} \mathrm{H}_{2} \mathrm{O}\right)$ desses solos se encontram-se entre 5,0 e 5,5 no horizonte $A$ (moderadamente ácidos), com um valor médio de 5,3 ; enquanto que no horizonte $B$ os valores oscilam entre 4,7 e 5,4, com um valor médio de 5,0. As variaçōes ao longo do perfil são relativamente pequenas. Os valores de $\mathrm{pH}$ em $\mathrm{KCl}$ se mostraram levemente inferiores aos valores de $\mathrm{pH}$ em água, - que significa que há uma predominância de cargas negativas no complexo coloidal (cf. Tabela 3 e 4).

Os valores encontrados para a soma das bases $(S)$ são muito baixos no horizonte $A$, entre 0,6 e $1,7 \mathrm{mEq} / 100 \mathrm{~g}$, com um valor médio de 1,1 $\mathrm{mEq} / 100 \mathrm{~g}$. São mais baixos ainda no horizonte $B$, entre 0,4 a 1,9 mEq/100g, com um valor médio de $0,9 \mathrm{mEq} / 100 \mathrm{~g}$. A saturaçāo de bases $(\mathrm{V} \%)$ é baixa no horizonte A. Oscila entre 12,7 e 31,1\%, com um valor médio de $20,0 \%$. No horizonte $B$ oscila ente 9,7 e 30,0\%, com um valor médio de 17,4\%. De 24 amostras analisadas, 16 apresentaram saturação de bases entre 10 e 20\% (cf. Tabelas 3, 4 e 5).

O alumínio trocável $\left(\mathrm{Al}^{+++}\right)$no horizonte A possui valores variando de 0,2 a $0,6 \mathrm{mEq} / 100 \mathrm{~g}$ e um valor médio de $0,3 \mathrm{mEq} / 100 \mathrm{~g}$. Oscila de 0,1 a $0,7 \mathrm{mEq} / 100 \mathrm{~g}$ no horizonte $B$, com um valor médio de $0,3 \mathrm{mEq} / 100 \mathrm{~g}$. A saturação em alumínio $\left(100 . \mathrm{Al}^{+++} / \mathrm{Al}^{+++}+\mathrm{S}\right)$ varia de 12,5 a $48,0 \%$ no horizonte $A$, com um teor médio de $25,7 \%$. No horizonte $B$, varia de 13,7 a $41,2 \%$, com um teor médio de $26,8 \%$. Esses solos sāo classificados como distróficos. De 24 amostras analisadas 16 apresentaram saturação de alumínio entre 10 e 30\% (cf. Tabela 3, 4 e 6).

A capacidade de troca catiônica $(T)$ no horizonte $A$ apresentou valores variando de 4,5 a $6,8 \mathrm{mEq} / 100 \mathrm{~g}$ e um valor médio de $5,5 \mathrm{mEq} / 100 \mathrm{~g}$. 
No horizonte $B$, essa variação se encontra entre 4,0 a $6,8 \mathrm{mEq} / 100 \mathrm{~g}$ (cf. Tabela 3 e 4). Apresentamos, após as tabelas, descrição morfológica de alguns perfis de solo da unidade AREIAS QUARTZOSAS.

TABELA 1 - Distribuição textural do horizonte A dos solos da unidade AREIAS QUARTZOSAS (\%)

\begin{tabular}{l|c|c|c|c|c}
\hline & Textura & Amostras & Média & Mínima & Máxima \\
\hline \multirow{4}{*}{ Horizonte } & Areia Grossa & 14 & 28,2 & 22,9 & 37,8 \\
A & Areia Fina & 14 & 53,1 & 47,3 & 58,6 \\
& Areia & 14 & 80,0 & 78,6 & 94,0 \\
& Silte & 14 & 4,4 & 0,4 & 11,0 \\
& Argila & 14 & 11,9 & 5,7 & 15,8 \\
\hline
\end{tabular}

TABELA 2 - Distribuição textural do horizonte B dos solos da unidade AREIAS QUARTZOSAS (\%)

\begin{tabular}{l|c|c|c|c|c}
\hline & Textura & Amostras & Média & Mínima & Máxima \\
\hline \multirow{4}{*}{ Horizonte } & Areia Grossa & 23 & 23,8 & 4,5 & 35,0 \\
B & Areia Fina & 23 & 55,6 & 45,5 & 73,6 \\
& Areia & 23 & 79,4 & 75,8 & 89,7 \\
& Silte & 23 & 4,7 & 1,2 & 15,8 \\
& Argila & 23 & 15,2 & 7,1 & 27,4 \\
\hline
\end{tabular}

TABELA 3 - Características químicas do horizonte A dos solos da unidade AREIAS QUARTZOSAS

\begin{tabular}{|c|c|c|c|c|c|}
\hline & Parâmetro (mEq/100g) & Amostras & Média & Mínima & Máxima \\
\hline & $\mathrm{pH}\left(\mathrm{H}_{2} \mathrm{O}\right)$ & 9 & 5,3 & 5,0 & 5,5 \\
\hline & $\mathrm{pH}(\mathrm{KCL})$ & 9 & 4,2 & 4,2 & 4,4 \\
\hline & $\mathrm{Ca}^{++}$ & 9 & 0,4 & 0,3 & 0,6 \\
\hline Horizonte & $\mathrm{Mg}^{++}$ & 9 & 0,6 & 0,3 & 1,1 \\
\hline A & $\mathrm{Na}^{+}$ & 9 & 0,03 & 0,00 & 0,23 \\
\hline & $\mathrm{K}^{+}$ & 9 & 0,06 & 0,00 & 0,21 \\
\hline & $\mathrm{Al}^{+++}$ & 9 & 0,3 & 0,2 & 0,6 \\
\hline & $\mathrm{H}^{+}$ & 9 & 4,1 & 2,9 & 5,1 \\
\hline & $S$ & 9 & 1,1 & 0,6 & 1,7 \\
\hline & $\mathrm{T}$ & 9 & 5,5 & 4,5 & 6,8 \\
\hline & $V(1)$ & 9 & 20,0 & 12,7 & 31,1 \\
\hline & $100 . \mathrm{Al}^{3+} / \mathrm{Al}^{3+}+\mathrm{S}(\mathrm{em} \%)$ & 9 & 25,7 & 12,5 & 48,0 \\
\hline
\end{tabular}

(1) $\mathrm{V}(\mathrm{em} \%)$

(2) $100 . \mathrm{Al}^{3+} / \mathrm{Al}^{3+}+\mathrm{S}(\mathrm{em} \%)$ 
TABELA 4 - Características químicas do horizonte B dos solos da unidade AREIAS QUARTZOSAS.

\begin{tabular}{c|c|c|c|c|c}
\hline & Parâmetro (mEq/100g) & Amostras & Média & Mínima & Máxima \\
\cline { 2 - 6 } Horizonte & $\mathrm{pH}\left(\mathrm{H}_{2} \mathrm{O}\right)$ & 15 & 5,0 & 4,7 & 5,4 \\
$\mathrm{BH}(\mathrm{KCL})$ & 15 & 4,3 & 4,1 & 4,8 \\
& $\mathrm{Ca}^{++}$ & 15 & 0,3 & 0,1 & 0,4 \\
& $\mathrm{Mg}^{++}$ & 15 & 0,5 & 0,1 & 1,3 \\
$\mathrm{Na}^{+}$ & 15 & 0,02 & 0,00 & 0,07 \\
& $\mathrm{~K}^{+}$ & 15 & 0,03 & 0,00 & 0,22 \\
& $\mathrm{Al}^{+++}$ & 15 & 0,3 & 0,1 & 0,7 \\
& $\mathrm{H}^{+}$ & 15 & 3,7 & 2,9 & 4,7 \\
$\mathrm{~S}$ & 15 & 0,9 & 0,4 & 1,9 \\
& $\mathrm{~T}$ & 15 & 4,8 & 4,0 & 6,8 \\
& $\mathrm{~V}(1)$ & 15 & 17,4 & 9,7 & 31,0 \\
& $100 . \mathrm{Al}^{3+} / \mathrm{Al}^{3+}+\mathrm{S}(\mathrm{em} \%)$ & 15 & 26,8 & 13,7 & 41,2 \\
\hline
\end{tabular}

(1) $\mathrm{V}(\mathrm{em} \%)$

(2) $100 . \mathrm{Al}^{3+} / \mathrm{Al}^{3+}+\mathrm{S}(\mathrm{em} \%)$

TABELA 5 - Saturação de bases dos solos da unidade AREIAS QUARTZOSAS

\begin{tabular}{c|c}
\hline Classes (mEq/100g) & Freqüência \\
\hline $00-10$ & 1 \\
$10-20$ & 16 \\
$20-30$ & 5 \\
$30-40$ & 2 \\
$40-50$ & 0 \\
Total & 24 \\
\hline
\end{tabular}

TABELA 6 - Saturação de alumínio dos solos da unidade AREIAS QUARTZOSAS

\begin{tabular}{l|c}
\hline Classes $(\mathrm{mEq} / 100 \mathrm{~g})$ & Freqüência \\
\hline $0-10$ & 0 \\
$10-20$ & 8 \\
$20-30$ & 8 \\
$30-40$ & 6 \\
$40-50$ & 2 \\
Total & 24 \\
\hline
\end{tabular}

PERFIL 16

DATA - 6/5/92

CLASSIFICAÇĀO: Latossolo Vermelho-amarelo distrófico textura média

LOCALIZAÇĀO: 19¹1'40"S e 4819'06'W

SITUAÇÃO: corte de estrada

ALTITUDE: $841 \mathrm{~m}$

LITOLOGIA: Arenito Marília

PEDREGOSIDADE: não pedregosa

ROCHOSIDADE: não rochosa

RELEVO LOCAL: Sub-plano, declividade $<3 \%$

RELEVO REGIONAL: suave ondulado

EROSĀO: nāo aparente

DRENAGEM:fortemente drenado

VEGETAÇĀO PRIMÁRIA: cerrado

USO ATUAL: pastagem

CLIMA: CW de Köppen

DESCRITOE COLETADOPOR: Samuel do Carmo Lima

\section{DESCRIÇÃO MORFOLÓGICA:}

A1 $(0$ a $9 \mathrm{~cm})$ - cor 7,5 YR $3 / 4$, bruno esuro, textura arenosa; estrutura fraca a moderada, pequena granular; macio, friável, não plástico e não pegajoso, 
areia lavada; pequenos fragmentos de carvão; raízes abundantes até $10 \mathrm{~cm}$ de profundidade; transição plana e gradual;

A3 (9 a $18 \mathrm{~cm})$ - cor 7,5 YR 4/4, bruno escuro, textura arenosa, estrutura fraca pequena granular; macio, friável, ligeiramente plástico e ligeiramente pegajoso, transição plana e gradual;

B1 (18 a $35 \mathrm{~cm})$ - cor 7,5 YR 4/4, bruno escuro, levemente mais claro que o sub-horizonte superior; textura arenosa; estrutura fraca pequena granular; macio, friável, ligeiramente plástico e ligeiramente pegajoso, transição plana e gradual;

B21 (35 a $65 \mathrm{~cm})$ - cor 7,5 YR 4/6, bruno forte, textura arenosa; estrutura fraca pequena granular; friável, ligeiramente plástico e ligeiramente pegajoso, presença de cupim e pedotubulos de secção transversal de mais ou menos $1 \mathrm{~mm}$; transição plana e gradual;

B22 (65 a $150 \mathrm{~cm}+)$ - cor 7,5 YR 5/6; bruno forte, textura arenosa, estrutura muito pequena fraca granular; friável, ligeiramente plástico eligeiramente pegajoso.

\section{PERFIL 17}

DATA - 6/5/92

CLASSIFICAÇĀO: Latossolo Vermelho-amarelo distrófico textura média

LOCALIZAÇĀO: 19¹3'54" S e 48'16'54"

SITUAÇĀO: corte de estrada

ALTITUDE: $880 \mathrm{~m}$

LITOLOGIA: arenito Marília

PEDREGOSIDADE: não pedregosa

ROCHOSIDADE: não rochosa

RELEVO LOCAL: plana

RELEVO REGIONAL: suave ondulado

EROSĀO: não aparente

DRENAGEM: fortemente drenado

VEGETAÇĀO PRIMÁRIA: cerrado

USO ATUAL: pastagem

CLIMA: CW de Köppen

DESCRITOE COLETADO POR: Samuel do Carmo Lima

\section{DESCRIÇĀO MORFOLÓGICA:}

A1 $(0$ a $10 \mathrm{~cm})$ - cor 7,5 YR 4/4, bruno escuro textura arenosa; estrutura fraca pequena granular; ligeiramente duro, friável, não plástico e não pegajoso, raízes abundantes; transiçāo plana e gradual;

A3 $(10 \mathrm{a} 18 \mathrm{~cm})$ - cor 5 YR 4/4, bruno avermelhado, textura areno-argilosa; estrutura fraca pequena granular; ligeiramente duro, friável, nāo plástico e não pegajoso, areia lavada; transição plana e gradual;

B1 (18 a $52 \mathrm{~cm})$ - cor 5 YR 4/4, bruno avermelhado, textura areno-argilosa, diminuem raízes, somente finas; estrutura fraca pequena granular; macio e friável, ligeiramente plástico e ligeiramente pegajoso, transição plana e gradual;

B21 (52 a $75 \mathrm{~cm})$ - cor 5 YR 4/6; vermelho amarelo, textura areno-argilosa; estrutura fraca pequena granular; macio e friável, ligeiramente plástico e ligeiramente pegajoso, transiçāo plana e gradual;

B22 (75 a $152 \mathrm{~cm} \mathrm{+)} \mathrm{-} \mathrm{cor} 5$ YR 5/6; vermelho amarelo, textura areno-argilosa, estrutura fraca pequena granular, macio e friável, ligeiramente plástico e ligeiramente pegajoso.

PERFIL 18

DATA - 6/5/92

CLASSIFICAÇĀO: Latossolo Vermelho-amarelo distrófico textura média

LOCALIZAÇĀO: 19॰14'03" S e ${ }^{480} 16^{\prime} 26^{\prime \prime} \mathrm{W}$

SITUAÇĀO: corte de estrada

ALTITUDE: $843 \mathrm{~m}$

LITOLOGIA: arenito Marília

PEDREGOSIDADE: não pedregosa

ROCHOSIDADE: não rochosa

RELEVO LOCAL: Sub-plano, declividade $<3 \%$

RELEVO REGIONAL: suave ondulado

EROSÃO: não aparente

DRENAGEM: fortemente drenado

VEGETAÇĀO PRIMÁRIA: cerrado

USO ATUAL: pastagem

CLIMA: Cw de Köppen

DESCRITOE COLETADOPOR: Samuel do Carmo Lima

\section{DESCRIÇĀO MORFOLÓGICA:}

A1 $(0 \mathrm{a} 8 \mathrm{~cm})$ - $\operatorname{cor} 7,5$ YR $3 / 4$, bruno escuro, textura arenosa; estrutura fraca pequena granular, que se desfaz em grāos simples, muito friável; areia lavada; pequenos fragmentos de carvão; raízes abundantes não plástico e não pegajoso; transiçāo plana e gradual; 
A3 $(8$ a $16 \mathrm{~cm})$ - cor 7,5 YR 4/4, bruno escuro, textura arenosa; estrutura fraca pequena a média granular; areia lavada; maior quantidade fragmentos de carvāo de tamanho centimétrico; diminuem as raízes; solto a macio, friável, ligeiramente plástico e ligeiramente pegajoso, transição plana e gradual;

B1 (16 a $38 \mathrm{~cm})$ - cor 7,5 YR 4/6, bruno forte, textura arenosa; estrutura fraca pequena a média granular; macio e friável, ligeiramente plástico e ligeiramente pegajoso, transição plana e gradual;

B21 (38 a $70 \mathrm{~cm})$ - cor 7,5 YR 4/6, bruno forte, textura arenosa; estrutura fraca pequena granular; macio efriável, ligeiramente plástico e ligeiramente pegajoso, presença de cupim e pedotubulos de secção transversal de mais ou menos $1 \mathrm{~mm}$; transição plana e gradual;

B22 (70 a $148 \mathrm{~cm}+)$ - cor 7,5 YR 5/6, bruno forte, textura arenosa, estrutura estrutura fraca pequena granular; macio e friável, ligeiramente plástico e ligeiramente pegajoso.

PERFIL 19

DATA - 6/5/92

CLASSIFICAÇĀO: Latossolo Vermelho-amarelo distrófico textura média

LOCALIZAÇÃO: 19014"09" S e 4817'04" W

SITUAÇĀO: corte de estrada

ALTITUDE: $859 \mathrm{~m}$

LITOLOGIA: arenito Marília

PEDREGOSIDADE: nāo pedregosa

ROCHOSIDADE: não rochosa

RELEVO LOCAL: plana

RELEVO REGIONAL: suave ondulado

EROSĀO: nāo aparente

DRENAGEM: fortemente drenado

VEGETAÇĀO PRIMÁRIA: cerrado

USO ATUAL: pastagem

CLIMA: Cw de Köppen

DESCRITOE COLETADOPOR:Samuel do Carmo Lima

\section{DESCRIÇÃO MORFOLÓGICA:}

A1 (0 a $11 \mathrm{~cm})$ - cor 5 YR 4/4, bruno avermelhada, textura arenosa; estrutura fraca pequena granular; macio, friável, nāo plástico e nāo pegajoso, raízes abundantes; areialavada; transição plana e gradual;
A3 (11 a $19 \mathrm{~cm})$ - cor 5 YR 4/6, vermelho amarelo, textura arenosa; estrutura fraca pequena granular; macio, friável, ligeiramente plástico e ligeiramente pegajoso, areialavada; transiçāo plana e gradual;

B1 (19 a $52 \mathrm{~cm})$ - cor 5 YR 4/6, vermelho amarelo, textura arenosa, levemente mais argilosa que o sub-horizonte superior; diminuem raízes; estrutura fraca pequena granular; macio, friável, ligeiramente plástico e ligeiramente pegajoso, transiçāo plana e gradual;

B21 $(52$ a $73 \mathrm{~cm})$ - cor 5 YR 4/6, vemelho amarelo, textura areno-argilosa; estrutura fraca muito pequena granular; macio e friável, ligeiramente plástico e ligeiramente pegajoso, transição plana e gradual;

B22 (73 a $150 \mathrm{~cm}+)$ - cor 5 YR 5/6, vermelho amarelo, textura areno-argilosa, estrutura fraca muito pequena granular, macio e friável, ligeiramente plástico e ligeiramente pegajoso.

\section{2 - Unidade LATOSSOLOS}

Essa unidade apresenta Latossolos Vermelho-amarelos, de cores 5YR e 7,5YR bem homogêneas ao longo do perfil, distróficos, de textura média. A distribuiçāo da argila apresenta teores que crescem em profundidade, porém, com baixa gradiência textural. Esses solos ocupam uma área de $186,2 \mathrm{Km}^{2}$, equivalente a $80,6 \%$ da área total da bacia.

O horizonte $A$ possui espessura variando de 18 a $30 \mathrm{~cm}$, com transição clara e plana para o horizonte B. O horizonte B possui espessura média variando entre $30 \mathrm{~cm}$ e mais que $190 \mathrm{~cm}$ de profundidade. A textura no horizonte $A$ apresenta teores de areia variando de 66,3 a 86,6\% e um teor médio de $79,3 \%$. No horizonte $B$ a textura varia de 59,4 a $83,7 \%$ e um teor médio de $77,5 \%$. Os teores de argila variam de 8,8 a $20,8 \%$, com um valor médio de $13,1 \%$ no horizonte $A$ e de 11,2 a 22,9\% no horizonte $B$, com um valor médio de $16,2 \%$. (cf. Tabela 7 e 8). 
TABELA 7 - Distribuição textural do horizonte A dos solos da unidade LATOSSOLOS (\%)

\begin{tabular}{l|c|c|c|c|c}
\hline & Textura & Amostras & Média & Mínima & Máxima \\
\hline & Areia Grossa & 16 & 24,6 & 14,6 & 32,7 \\
& Areia Fina & 16 & 56,9 & 49,7 & 68,0 \\
Horizonte & Areia & 18 & 79,3 & 66,3 & 86,6 \\
A & Silte & 18 & 4,1 & 2,2 & 12,9 \\
& Argila & 18 & 13,1 & 8,8 & 20,8 \\
\hline
\end{tabular}

A estrutura no horizonte $A$ é fraca pequena granular. A consistência é macia, não plástica e nāo pegajosa. A cor é bruno avermelhado 5 YR 4/4 a 4/6, levemente mais escurecido que o horizonte $\mathrm{B}$, demonstrando um baixo conteúdo de matéria orgânica. A estrutura no horizonte B é microagregada e a consistência semelhante à do horizonte A. A cor é bruno amarelado 5 YR 4/4 a 5/ 6.

Os valores de $\mathrm{pH}\left(\mathrm{H}_{2} \mathrm{O}\right)$ desses solos encontram-se entre 4,9 e 5,9 no horizonte $A$, com um valor médio de 5,2. No horizonte $\mathrm{B}$ o pH $\left(\mathrm{H}_{2} \mathrm{O}\right)$ situam-se entre 4,5 e 5,3, com um valor médio de 5,0 . Os valores de $\mathrm{pH}(\mathrm{KCl})$ se mostraram inferiores, entre 4,0 e 4,4, tanto no horizonte $A$ quanto no horizonte B (cf. Tabelas 9 e 10).

A soma das bases (S) apresentou valores muito baixos, variando de 0,6 a 1,6 mEq/ $100 \mathrm{~g}$, com um valor médio de $1,1 \mathrm{mEq} / 100 \mathrm{~g}$ no horizonte $A$. No horizonte $B$ a variação ficou entre 0,5 a $1,0 \mathrm{mEq} / 100 \mathrm{~g}$, com um valor médio de 0,8 $\mathrm{mEq} / 100 \mathrm{~g}$. Os valores de saturaçāo em bases (V\%) são também muito baixos, com valores entre 11,1 e $27,5 \%$ no horizonte $A$, com um valor médio de $20,2 \%$; e entre 9,8 e $20,0 \%$ no horizonte $B$, com um valor médio de 15,5\%. De 20 amostras analisadas 14 apresentaram saturação de base entre 10 e $20 \%$ (cf. Tabelas 9, 10 e 11).

TABELA 8 - Distribuição textural do horizonte B dos solos da unidade LATOSSOLOS (\%)

\begin{tabular}{l|c|c|c|c|c}
\hline & Textura & Amostras & Média & Mínima & Máxima \\
\hline \multirow{4}{*}{ Horizonte } & Areia Grossa & 37 & 23,2 & 15,7 & 29,6 \\
A & Areia Fina & 37 & 54,1 & 41,9 & 65,7 \\
& Areia & 43 & 77,5 & 59,4 & 83,7 \\
& Silte & 43 & 4,4 & 2,4 & 19,1 \\
& Argila & 43 & 16,2 & 11,2 & 22,9 \\
\hline
\end{tabular}

O alumínio trocável $\left(\mathrm{Al}^{+++}\right)$varia de 0,1 a $0,8 \mathrm{mEq} / 100 \mathrm{~g}$ no horizonte $A$, com um valor médio de 0,4 , e varia de 0,2 a 0,8 no horizonte $B$, com um valor médio de 0,4 . A saturaçāo em alumínio (100.Al+++/Al+++ + S) situa-se entre 8,8 e $49,1 \%$ no horizonte $A$, com um valor médio de $26,7 \%$; e no horizonte B essa variação situa-se entre 18,9 e $50,0 \%$, com um valor médio de $34,71 \%$. De 20 amostras analisadas, 8 apresentaram saturação de alumínio entre 10 e $30 \%, 5$ amostras entre 30 e $40 \%$ e 6 amostras apresentaram saturação de alumínio entre 40 e $50 \%$. Esses solos são classificados como distróficos (cf. Tabelas 9, 10 e 12).

A capacidade de troca catiônica ( $T$ ) apresentou valores variando de 4,0 a $6,8 \mathrm{mEq} /$ $100 \mathrm{~g}$ no horizonte $\mathrm{A}$, com um valor médio de 5,5 
$\mathrm{mEq} / 100 \mathrm{~g}$. No horizonte $B$ essa variação se apresentou entre 4,5 a $5,9 \mathrm{mEq} / 100 \mathrm{~g}$, com um valor médio de $5,3 \mathrm{mEq} / 100 \mathrm{~g}$ (cf. Tabelas 9 e 10).
Apresentamos, após as tabelas, a descrição morfológica de alguns perfis de solo da unidade LATOSSOLOS.

TABELA 9 - Características químicas do horizonte A dos solos da unidade LATOSSOLOS

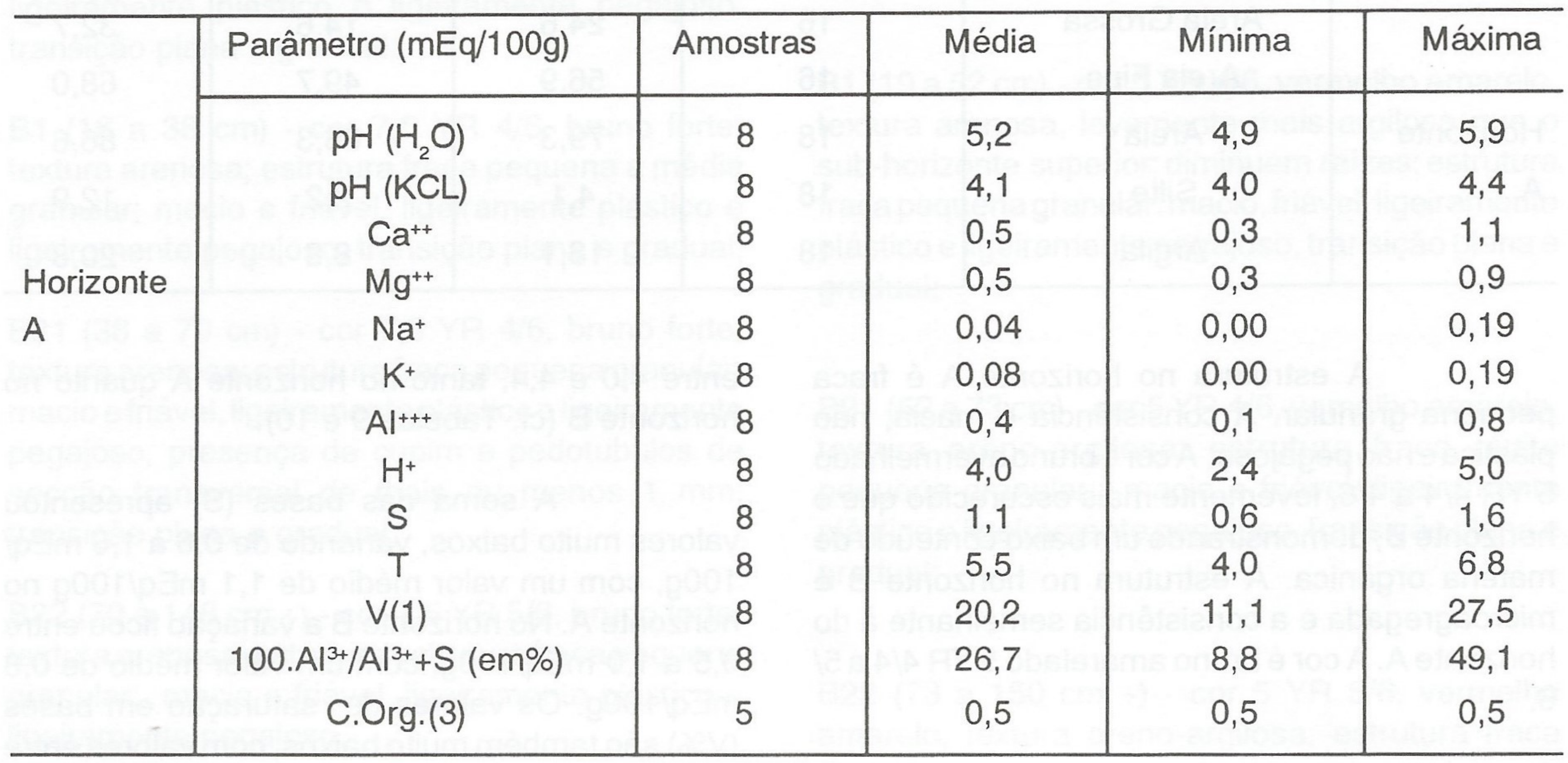

(1) $\mathrm{V}(\mathrm{em} \%)$

(2) C.Org. (em \%)

(3) $100 . \mathrm{Al}^{3+} / \mathrm{Al}^{3+}+\mathrm{S}(\mathrm{em} \%)$

TABELA 10 - Características químicas do horizonte B dos solos da unidade LATOSSOLOS

\begin{tabular}{|c|c|c|c|c|c|}
\hline & Parâmetro (mEq/100g) & Amostras & Média & Mínima & Máxima \\
\hline & $\mathrm{pH}\left(\mathrm{H}_{2} \mathrm{O}\right)$ & 12 & 5,0 & 4,5 & 5,3 \\
\hline & $\mathrm{pH}(\mathrm{KCL})$ & 12 & 4,2 & 4,0 & 4,4 \\
\hline & $\mathrm{Ca}^{++}$ & 12 & 0,4 & 0,3 & 0,7 \\
\hline Horizonte & $\mathrm{Mg}^{++}$ & 12 & 0,3 & 0,2 & 0,7 \\
\hline \multirow[t]{9}{*}{ B } & $\mathrm{Na}^{+}$ & 12 & 0,04 & 0,00 & 0,16 \\
\hline & $\mathrm{K}^{+}$ & 12 & 0,03 & 0,00 & 0,10 \\
\hline & $\mathrm{Al}^{+++}$ & 12 & 0,4 & 0,2 & 0,8 \\
\hline & $\mathrm{H}^{+}$ & 12 & 4,0 & 3,3 & 4,8 \\
\hline & $S$ & 12 & 0,8 & 0,5 & 1,0 \\
\hline & $T$ & 12 & 5,3 & 4,5 & 5,9 \\
\hline & $V(1)$ & 12 & 15,5 & 9,8 & 20,0 \\
\hline & 100. $\mathrm{Al}^{3+} / \mathrm{Al}^{3+}+\mathrm{S}(\mathrm{em} \%)$ & 12 & 34,7 & 18,9 & 50,0 \\
\hline & C.Org. (3) & 10 & 0,2 & 0,2 & 0,3 \\
\hline
\end{tabular}

(1) $\mathrm{V}(\mathrm{em} \%)$

(2) C. Org. (em \%)

(3) $100 . \mathrm{Al}^{3+} / \mathrm{Al}^{3+}+\mathrm{S}(\mathrm{em} \%)$

Sociedade \& Natureza, Uberlândia, 4 (7 e 8): 85-98, janeiro/dezembro 1992 
TABELA 11 - Saturação de base dos solos da unidade LATOSSOLOS

\begin{tabular}{l|c}
\hline Classes (mEq/100g) & Freqüência \\
\hline $0-10$ & 1 \\
$10-20$ & 14 \\
$20-30$ & 5 \\
$30-40$ & 0 \\
$40-50$ & 0 \\
Total & 20 \\
\hline
\end{tabular}

TABELA 12 - Saturação de alumínio dos solos da unidade LATOSSOLOS

\begin{tabular}{l|c}
\hline Classes $(\mathrm{mEq} / 100 \mathrm{~g})$ & Freqüência \\
\hline $0-10$ & 1 \\
$10-20$ & 3 \\
$20-30$ & 5 \\
$30-40$ & 5 \\
$40-50$ & 6 \\
Total & 20 \\
\hline
\end{tabular}

PERFIL 20

DATA - 6/5/92

CLASSIFICAÇĀO: Areia Quartzosa distrófica

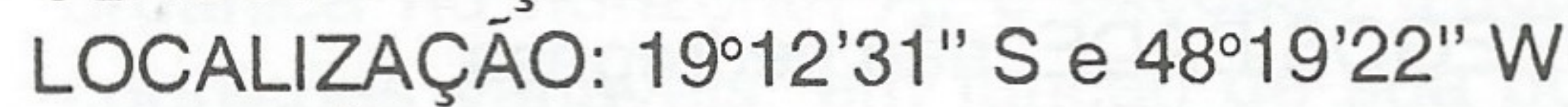

SITUAÇĀO: corte de estrada

ALTITUDE: $821 \mathrm{~m}$

LITOLOGIA: arenito Marília

PEDREGOSIDADE: não pedregosa

ROCHOSIDADE: nāo rochosa

RELEVO LOCAL: Sub-plano, declividade $<3 \%$

RELEVO REGIONAL: suave ondulado

EROSĀO: não aparente

DRENAGEM: fortemente drenado

VEGETAÇĀO PRIMÁRIA: cerrado

USO ATUAL: pastagem

CLIMA: CW de Köppen

DESCRITO E COLETADO POR: Samuel do

Carmo Lima

DESCRIÇĀO MORFOLÓGICA: arenosa; estrutura fraca pequena granular; areia lavada; raízes abundantes; ligeiramente duro, muito friável, não plástico e não pegajoso, transição plana e gradual;

A3 (9 a $15 \mathrm{~cm})$ - cor 7,5 YR 4/4, bruno escuro, textura arenosa; estrutura maciça porosa que se desfaz em blocos subangulares médios; areia lavada; maior quantidade de fragmentos de carvão de tamanho centimétrico; diminuem as raízes; macio, muito friável, nāo plástico e nāo pegajoso, transição plana e gradual;

C1 (15 a $41 \mathrm{~cm})$ - cor 7,5 YR 5/6, bruno forte, textura arenosa, levemente mais argilosa que o sub-horizonte anteririor; estrutura maciça porosa pouco coerente; macio, muito friável, nāo plástico e não pegajoso, transição plana e difusa;

C2 (41 a $84 \mathrm{~cm})$ - cor 7,5 YR 4/4, bruno escuro, mais escurecido que o sub-horizonte acima; textura arenosa; presença de cupim e pedotubulos de secção transversal de mais ou menos $1 \mathrm{~mm}$; estrutura maciça porosa pouco coerente; macio, muito friável, não plástico e não pegajoso, transição plana e gradual;

C3 (84 a $180 \mathrm{~cm}+)$ - cor 7,5 YR 5/6, bruno forte, textura arenosa, estrutura maciça porosa pouco coerente; macio, muito friável, não plástico e não pegajoso.

\section{PERFIL 21}

DATA - 6/5/92

CLASSIFICAÇĀO: Areia Quartzosa Distrófica LOCALIZAÇÂO: 19¹2'06" S e 48²0'18' W

SITUAÇĀO: corte de estrada

ALTITUDE: $845 \mathrm{~m}$

LITOLOGIA: Cobertura Detrito-Laterítica -

Cenozóica

PEDREGOSIDADE: não pedregosa

ROCHOSIDADE: não rochosa

RELEVO LOCAL: plana

RELEVO REGIONAL: suave ondulado

EROSĀO: não aparente

DRENAGEM: fortemente drenado

VEGETAÇĀO PRIMÁRIA: cerrado

USO ATUAL: pastagem

CLIMA: $\mathrm{Cw}$ de Köppen

DESCRITO E COLETADO POR: Samuel do Carmo Lima

A1 $(0$ a $9 \mathrm{~cm})-\operatorname{cor} 7,5 \mathrm{YR} 3 / 4$, bruno escuro, textura 


\section{DESCRIÇĀO MORFOLÓGICA:}

A1 $(0 \mathrm{a} 8 \mathrm{~cm})-\operatorname{cor} 7,5$ YR $4 / 4$, bruno escuro, textura arenosa; estrutura fraca pequena granular; raízes abundantes; ligeiramente duro, friável, não plástico e não pegajoso, transição plana e gradual;

A3 (9 a $23 \mathrm{~cm})$ - cor 7,5 YR 4/4 bruno escuro, textura arenosa; estruturafraca pequena granular; ligeiramente duro, friável, nāo plástico e não pegajoso, areia lavada; transiçăo plana e gradual;

C1 $(23$ a $55 \mathrm{~cm})$ - cor 7,5 YR 4/6 bruno forte, textura arenosa, levemente mais argilosa que o sub-horizonte anterior; estrutura fraca pequena granular, com aspecto de maciça porosa pouco coerente, mais úmido; macio, friável, não plástico e não pegajoso; transição plana e gradual;

C2 (55 a $83 \mathrm{~cm})$ - cor 7,5 YR 5/6, bruno forte, textura arenosa; estrutura fraca muito pequena granular, macio, friável, não plástico e não pegajoso; transição plana e gradual;

C3 (83 a $164 \mathrm{~cm} \mathrm{+)} \mathrm{-} \mathrm{cor} \mathrm{7,5} \mathrm{YR} \mathrm{5/8,} \mathrm{bruno} \mathrm{forte,}$ textura arenosa, estrutura fraca muito pequena granular, macio, friável, não plástico e não pegajoso.

PERFIL 22

DATA - 6/5/92

CLASSIFICAÇĀO: Areia Quartzosa Distrófica

LOCALIZAÇÄO: 19'12'26" S e 48'19'54" W

SITUAÇĀO: corte de estrada

ALTITUDE: $827 \mathrm{~m}$

LITOLOGIA: Cobertura Detrito-Laterítica -

Cenozóica

PEDREGOSIDADE: nāo pedregosa

ROCHOSIDADE: nāo rochosa

RELEVO LOCAL: suave ondulado

RELEVO REGIONAL: suave ondulado

EROSĀO: não aparente

DRENAGEM: fortemente drenado

VEGETAÇĀO PRIMÁRIA: cerrado

USO ATUAL: pastagem

CLIMA: CW de Köppen

DESCRITO E COLETADO POR: Samuel do

Carmo Lima

\section{DESCRIÇĀO MORFOLÓGICA:}

A1 $(0$ a $12 \mathrm{~cm})$ - cor 7,5 YR 4/6, bruno forte; textura arenosa; estrutura fraca a moderada pequena granular; macio, muito friável, não plástico e não pegajoso raízes abundantes; areia lavada; transiçāo plana e gradual;

A3 (12 a $23 \mathrm{~cm})$ - cor 7,5 YR 5/6, bruno forte, textura arenosa; estrutura maciça porosa, constituida de grāo simples, macio, muito friável, não plástico e não pegajoso, diminuem raízes; areia lavada; transição plana e gradual;

B1 $(23$ a $56 \mathrm{~cm})$ - cor 5 YR 4/6, vermelho amarelo, textura arenosa, areia lavada abundante; estrutura maciça porosa, constituida de grão simples; macio, muito friável, não plástico e não pegajoso, transição plana e gradual;

B21 (56 a $89 \mathrm{~cm}$ ) - cor 5 YR 5/6, vermelho amarelo, textura arenosa; estrutura maciça porosa, constituida de grāos simples; macio, muito friável, não plástico e não pegajoso, transição plana e gradual;

B22 (89 a $145 \mathrm{~cm} \mathrm{+)} \mathrm{-} \mathrm{cor} 5$ YR 5/8, vermelho amarelo, textura arenosa, estrutura maciça porosa constituida de grãos simples, macio, muito friável, não plástico e não pegajoso.

\section{PERFIL 24}

DATA - 6/5/92

CLASSIFICAÇĀO: Latossolo Vermelho-amarelo distrófico textura média

LOCALIZAÇĀO: 19॰14'12" S e 4817'36" W

SITUAÇĀO: corte de estrada

ALTITUDE: $850 \mathrm{~m}$

LITOLOGIA: arenito Marília

PEDREGOSIDADE: nāo pedregosa

ROCHOSIDADE: não rochosa

RELEVO LOCAL: suave ondulado

RELEVO REGIONAL: suave ondulado

EROSĀO: não aparente

DRENAGEM: fortemente drenado

VEGETAÇĀO PRIMÁRIA: cerrado

USO ATUAL: pastagem

CLIMA: Cw de Köppen

DESCRITO E COLETADO POR: Samuel do Carmo Lima

\section{DESCRIÇĀO MORFOLÓGICA:}

A1 (0 a $5 \mathrm{~cm})$ - cor 5 YR 4/6, vermelho amarelo, textura arenosa; estrutura moderada pequena granular; macio e friável, não plástico e não pegajoso, raízes abundantes; areia lavada; transiçāo plana e gradual; 
A3 $(5$ a $18 \mathrm{~cm})$ - cor 5 YR 5/6, vermelho amarelo, textura areno-argilosa; estrutura fraca pequena a média subangular; macio e friável, ligeiramente plástico e ligeiramente pegajoso, diminuem raízes; areia lavada; transição plana e gradual;

B1 (18 a $58 \mathrm{~cm})$ - cor 5 YR 5/6, vermelho amarelo, textura areno-argilosa, areia lavada abundante; estrutura fraca pequenaa média subangular; macio, friável, ligeiramente plástico e ligeiramente pegajoso, transição plana e gradual;

B21 $(52$ a $75 \mathrm{~cm})$ - cor 2,5 YR 4/6 vermelho escuro, textura areno-argilosa; estrutura fraca pequena a média subangular; macio e friável, ligeiramente plástico e ligeiramente pegajoso, transiçāo plana e gradual;

B22 (75 a $150 \mathrm{~cm}+)$ - cor 2,5 YR 5/6, vermelho escuro, textura areno-argilosa, estrutura fraca pequena a média subangular macio e friável, ligeiramente plástico e ligeiramente pegajoso.

\section{3 - Unidade HIDROMÓRFICOS}

Essa unidade foi identificada e mapeada com auxílio de fotografias aéreas e imagens TM/Landsat. São solos hidromórficos, localizados nos fundos chatos dos vales afluentes do Ribeirāo Panga, e mesmo em alguns setores desse, onde é baixa a incisão fluvial e os solos mal drenados. Esses solos apresentam textura predominantemente arenosa, alto teor de matéria orgânica no horizonte $A$, e excesso d'água em condiçōes variáveis, em funçāo de sua posiçāo relativa ao centro drenagem. Saao fortemente ácidos e de baixa fertilidade.

\section{Os solos da unidade} HIDROMÓRFICOS ocupam uma área de 33,49 $\mathrm{km} 2$, o que equivale a $14,3 \%$ da área total da bacia. Esses solos hidromórficos incluem os solos glei pouco húmico, glei húmico e orgânico, que são assim categorizados em função da espessura do horizonte $A$, do teor de matéria orgânica e da deficiência de drenagem, que nesse caso variam com a maior proximidade do eixo de drenagem.

Lima \& Bernardino (1993) apresentam dados que demonstram que as veredas não são o resultado de processos erosivos com entulhamento de vales. Sua origem está relacionada com um processo de arenização com perdas de argila no perfil e translocação de matéria orgânica em profundidade. Sāo solos "in situ", textura predominatemente arenosa, com transformaçōes pedogenéticas laterais e verticais de carater hidromórfico, com um pequeno capeamento aluviocoluvial.

As veredas são sub-sistemas úmidos dentro do cerrado caracterizados como sendo um vale de fundo chato, com uma zona de inundação permanente e outra de inundação essacional, cobertos por uma vegetaçāo rasteira, de gramíneas e ciperáceas, com buritizais. Na bacia do Ribeirāo Panga foram contadas 80 veredas (LIMA \& SILVEIRA 1991).

Ainda, encontram-se pequenas manchas de solos hidromórficos, não mapeáveis na escala de apresentação do mapa, nas vertentes em posiçōes de ruptura de declive. Estāo assentadas sobre couraças de ferro cascalhentas, que impedem a drenagem.

\section{4 - CONSIDERAÇÕES FINAIS}

Os solos da bacia do Ribeirāo Panga são classificados como sendo Latossolos Vermelho amarelos de textura média, com alto teor de areia fina, e Areias Quartzosas com inclusōes de Latossolos de textura arenosa. Os Latossolos possuem no horizonte $A$ estrutura fraca pequena granular e no horizonte $B$ é microagregada com aspecto de maciça pouco coerente. $O$ baixo teor de matéria orgânica está refletido na estrutura fraca pequena granular do horizonte A. As Areias Quartzosas possuem estrutura maciça porosa constituida de grãos simples, ou fraca pequena granular pouco coerente.

Os solos da bacia do Ribeirão Panga são mediana a fortemente ácidos, com características distróficas. Os teores de bases trocáveis são baixos, com também, os teores de alumínio trocáveis. A saturação de alumínio é relativamente baixa. Os cátions trocáveis estão mais concentrados na superfície, provavelmente devido à reciclagem biológica de nutrientes, acompanhando os teores de matéria orgânica. A capacidade de troca catiônica é um pouco mais elevada no horizonte $A$, no entanto os pontos de troca são ocupados quase que totalmente pelos íons ácidos, hidrogênio e alumínio, o que evidencia 
o intenso processo de lixiviação a que estão submetidos esses solos, resultantes de uma pedogênese sob clima tropical.

Entendendo fertilidade do solo como sendo a capacidade que o solo tem de ceder elementos essenciais às plantas, embora isto não dependa só das características físicas e químicas do solo, mas também da capacidade de absorção de nutrientes, que é diferente para cada espécie de planta, pode-se dizer que os solos da bacia do Ribeirāo Panga sāo de baixa fertilidade natural e boa estruturação física, como o são de modo geral os solos de cerrado.

\section{5 - REFERÊNCIAS BIBLIOGRÁFICAS}

CHRISTOFOLETTI, A. Geomorfologia Fluvial. Sāo Paulo, Ed. Edgard Blücher, 1974

EMBRAPA Manual de métodos de análise de solo. Rio de Janeiro, Serviço Nacional de Levantamento e Conservação de Solos, 1979a;

EMBRAPA Súmula da $X$ reuniāo técnica de levantamento de solos. Rio de Janeiro. Serviço Nacional de Levantamento e Conservação de Solos (séire Miscelânia, 1), 1979b;

EMBRAPA Levantamento de reconhecimento de média intensidade dos solos e avaliação da aptdāo agrícola das terras do Triângulo Mineiro. Rio de Janeiro. EMBRAPA-SNLCS/EPAMIG/ DRNR, 1982;
GOEDERT, W.J. Solos dos Cerrados - Tecnologias e estratégias de manejo.SãoPaulo. EMBRAPA/ NOBEL1986;

LIMA, S.C.; BERNARDINO, A.R. Caracterizaçāo das veredas como sub-sistemas úmidos do cerrado. DEGEO-UFU, Relatório Interno, 1993; LIMA, S.C.; SILVEIRA, F.P. A preservação das veredas para a manutençāo do equilíbrio hidrológico dos cursos d'água. Anais do $3^{\circ}$ Encontro Nacional dos Estudos sobre o Meio Ambiente. V. 1, Londrina, (PR), p. 204-218, 1991;

NISHIYAMA, L. Geologia do Município de Uberlândia e áreas adjacentes. Sociedade \& Natureza, Uberlândia, 1(1):09-16, 1989;

RADAMBRASIL Levantamento de recursos naturais. Rio de Janeiro. Ministério das Minas e Energia. Folha Goiânia, (31):421-435, 1983;

ROSA, R.; LIMA, S.C.; ASSUNÇĀO, W.L. Abordagem preliminar das condiçōes climáticas de Uberlândia, Sociedade \& Natureza. Uberlândia, 3(5 e 6):91-108, 1991;

SOIL SURVEY STAFF Soil taxonomy: a basic system of soil classification for making and interpreting soil survey. Washington, D.C., Department of Agricultura - USA, 1975. 